\title{
The Role of Water Depth Perception in Shaping Car Drivers' Intention to Enter Floodwaters: Experimental Evidence
}

\author{
Katerina Papagiannaki ${ }^{1, *(D)}$, Michalis Diakakis ${ }^{2, *(D)}$, Vassiliki Kotroni ${ }^{1}$ (D) $\operatorname{Kostas~Lagouvardos~}^{1} \operatorname{and}^{-}$ \\ Giorgos Papagiannakis ${ }^{3}$ (D) \\ 1 Institute of Environmental Research and Sustainable Development, National Observatory of Athens, \\ 11810 Athens, Greece; kotroni@noa.gr (V.K.); lagouvar@noa.gr (K.L.) \\ 2 Faculty of Geology and Geoenvironment, National and Kapodistrian University of Athens, \\ Panepistimioupoli, GR15784 Zografou, Greece \\ 3 Department of Economics, University of Peloponnese, 22100 Tripoli, Greece; papagiannakis@uop.gr \\ * Correspondence: katpap@noa.gr (K.P.); diakakism@geol.uoa.gr (M.D.)
}

Citation: Papagiannaki, K.; Diakakis, M.; Kotroni, V.; Lagouvardos, K.; Papagiannakis, G. The Role of Water Depth Perception in Shaping Car Drivers' Intention to Enter Floodwaters: Experimental Evidence. Sustainability 2021, 13, 4451. https:// doi.org/10.3390/su13084451

Academic Editor: Marilisa Botte

Received: 8 March 2021

Accepted: 13 April 2021

Published: 16 April 2021

Publisher's Note: MDPI stays neutral with regard to jurisdictional claims in published maps and institutional affiliations.

Copyright: (c) 2021 by the authors. Licensee MDPI, Basel, Switzerland. This article is an open access article distributed under the terms and conditions of the Creative Commons Attribution (CC BY) license (https:// creativecommons.org/licenses/by/ $4.0 /)$.

\begin{abstract}
Floods are one of the most lethal natural hazards. Recent studies show that in a large percentage of flood-related fatalities, victims engage in risk-taking behavior by getting deliberately in contact with floodwaters. This study integrates behavioral psychology and situational environmental factors with the aim to examine why individuals undertake such risky behavior. In particular, we draw on the theory of planned behavior (TPB) to link water depth perception with the intention of car drivers to enter floodwaters. The hypotheses on which the study was based were that the depth of the water adversely affects the driver's intention to enter floodwaters, and that this effect is mediated by a behavior-favorable attitude, a behavior-favorable subjective norm, and perceived behavioral control. Further, to understand the conditions under which this process works, the moderating role of past behavior in the above relationships is also examined. Results from an experimental study ( $n=1940)$ show that water depth perception affects intention. Attitude, perceived behavioral control, and normative beliefs operate as the underlying psychological mechanism that leads to the mitigation of intention in higher water depth situations. Interestingly, past risk-taking behavior is found to be a significant condition under which this process works, by mostly affecting individuals' attitudes. Mediation and moderated mediation analyses were conducted to estimate causal relationships. The findings provide evidence of the significant interaction that environmental, psychological, and precedent behavioral factors have on behavioral intentions.
\end{abstract}

Keywords: flood fatalities; risk-taking behavior; intention; TPB; past behavior; moderated mediation

\section{Introduction}

Despite the improvements in several aspects of flood risk management, including infrastructure and warning technology, floods remain one of the most lethal hazards. Recent catastrophic events have shown that floods still cause extensive human losses [1-3] along with damaging effects on infrastructure and socioeconomic activities. Recent studies provide a growing body of evidence indicating that risk-taking or dangerous behaviors are prevalent amongst flood victims [3-8]. Previous work has estimated that a significant portion of flood-victims, ranging from $43 \%$ to $90 \%$, pursue inappropriate, risk-taking actions during floods [7,9-12], even from an initial position of safety [12].

Surrounding environmental factors that could convey information about the level of danger and consequent risks are considered as a potentially critical element in the decision-making process, especially under stressful situations [13]. Research has shown that environmental risk-inducing factors such as rainfall are associated with the perception of risk and adaptive behavior during a severe flood event [14]. There is also evidence that environmental factors, such as the depth or the flow velocity, may influence the effects of risk perception on the willingness to enter floodwaters $[15,16]$. However, we know little 
about the effect of hazardous environmental cues as part of an integrated mechanism that leads to risk-taking behaviors of car drivers when they are confronted with floodwater.

To understand what forms individuals' behavior in such conditions, behavioral psychology is very informative [17]. Several studies have used well-established theoretical frameworks from the behavioral sciences, such as the theory of planned behavior (TPB) [17], to provide insights on the cognitive and psychological factors that affect the decisions of individuals to enter an inundated area and have attempted to explain why people drive into or avoid floodwaters $[15,16,18]$. These studies demonstrate that decisions are mostly psychological, and are influenced by a set of factors, including attitude, self-efficacy beliefs, social influence, risk perception, past experiences and behaviors, and other personal attributes. As behavior may also be influenced by environmental and situational factors, a theoretical perspective suggests psychology as a mediator of this relationship [17].

To explore the influence of the aforementioned factors on the intention or willingness to enter floodwaters, past studies have been mostly based on surveys [15,16,19-21]. However, one of the limitations of most studies concerns the potential biases of survey participants in comparison to individuals that experience the actual conditions of a flood, deriving from a lack of environmental cues and the absence of real-world decision-making. The main assumption of psychological models is that the examined behavior is a rational, well-thought process that is dictated by a specific goal or intention set by the individual [22]. However, real flood conditions or other situational factors can have an impact on the decision-making of an individual, compared to a survey aiming to describe his/her behavior by mentally simulating these conditions. Therefore, it would be beneficial to the performance of these models to provide an accurate specification or mental simulation of the real-world situations to confine the limitations that come together with the aforementioned assumption.

Drawing on the above, this study investigates whether a dynamic environmental factor such as water depth affects car drivers' intention to enter floodwaters, and whether the TPB operates as the underlying mechanism that explains why this happens, conditioned by past risk-taking behaviors. To that end, we adopted an experimental design and an imageryenriched questionnaire to simulate the conditions under which the critical decisions we analyze are taken. We randomly manipulated water depth perception to enhance the causal validity of our results. The experiment was conducted online and targeted the entire Greek population. Mediation and moderated mediation analyses were conducted to test the research model [23].

The results shed light on whether, why, and when environmental factors interact with personal beliefs and attitudes to affect the focal behavioral intention. The practical implications of the findings are related to the potential to apply tailored approaches to shape communication towards the citizens regarding the risks associated with entering floodwaters.

\section{Conceptual Framework and Hypotheses}

The conceptual framework of the research model (Figure 1) is based on the central hypothesis that psychological processes are involved in the decision of the individual to enter the floodwater while he/she has been provided with an environmental cue about the danger posed by the water depth. The research question, thus, is centered on the effect of an environmental situational factor on risk-taking intention, while exploring the underlying role of the TPB factors and conditions that stimulate this process.

Previous research indicates that under certain conditions, environmental factors may even constitute the prime determinant of motorists' behavior under hazardous weather events [24]. Furthermore, environmental factors, such as the level of inundation, water flow velocity, lightning, and rainfall, have been associated with avoiding entering floodwaters by Hamilton et al. [20]. Floodwater depth, in particular, has been shown to influence motorists' willingness to drive through a flooded waterway [16]. Drawing on the above, the following first hypothesis was made: 
Hypothesis 1 (H1). Water depth perception is negatively related to the driver's intention to enter floodwaters.

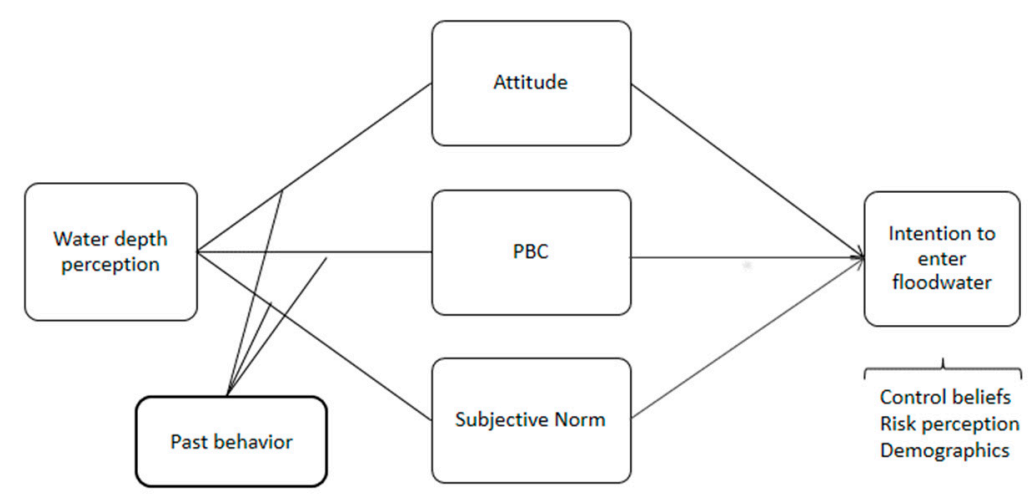

Figure 1. The research model of car drivers' intention to enter floodwaters. The model tests whether the theory of planned behavior (TPB) factors mediate the effect of water depth perception on car drivers' intention to enter floodwaters, and whether past behavior acts as a moderator in this process. Control beliefs, risk perception, and demographics serve as the control factors.

According to the TPB, introduced by Ajzen $[17,25]$, the performance of a behavior is predicted by the individual's intention to engage in it. Theoretically, the stronger the intention the more likely the behavior is to occur, given that the individual is free to choose what to do. In turn, behavioral intention is predicted by three basic elements: attitudes toward the behavior, perceived behavioral control (PBC), and subjective norms. Attitude refers to the degree to which the individual favors a particular behavior and its outcome or impact. PBC refers to the individual's perception of his/her ability to control and perform a particular behavior; thus, it entails the concept of self-efficacy [26]. Subjective norms refer to the belief that a particular behavior will be socially approved. A large number of empirical studies have proved the validity of the TPB in predicting behavioral intention in various social and health-related fields [27,28]. Moreover, previous research has shown the relevance of the TPB in explaining risk-taking behavior against weatherrelated hazards [16]. Therefore, motivated by the strong conviction that the TPB also has a practical application in the context of the present study, we considered the following second hypothesis in the context of our research model (Figure 1):

Hypothesis 2 (H2). The effect of water depth perception on the driver's intention to enter floodwaters is mediated by (a) a behavior-favorable attitude, (b) a behavior-favorable subjective norm, and (c) $P B C$.

In a broader context, the TPB suggests that background factors such as personality and experience may influence individuals' beliefs [29,30]. In several cases, the TPB has been extended to incorporate more parameters to explore their influence on the cognitive and psychological mechanisms through which motorists choose to enter floodwaters $[16,18]$. Some of the examined variables were found to increase the predictive ability of the traditional TPB, particularly past behaviors and experiences $[18,20]$. Therefore, in an attempt to identify the conditions under which the TPB mechanisms work, the following third hypothesis was made:

Hypothesis 3 (H3). Past behavior moderates the TPB-mediated relationship between water depth perception and the driver's intention to enter floodwaters.

The model also incorporates control factors, specifically control beliefs, risk perception, and demographics that have been found to affect individuals' intentions and behaviors $[15,29,31-33]$. Control beliefs associated with situational factors were also suggested 
to affect behavioral intention within the TPB framework [29,34,35]. Risk perception as a subjective assessment of the likelihood of personal and material damage has been suggested to contribute to the predictive ability of the TPB [16], although its association with behaviors against flood risks is still debated [36-38]. Among the demographic variables commonly used to complement analyses based on behavioral models, age and gender have been associated with drivers' intention to enter or avoid floodwaters $[12,20,39,40]$, although not consistently [41].

\section{Materials and Methods}

\subsection{Experiment}

A survey-based experiment [42,43] was performed to test the TPB model upon the three aforementioned research hypotheses. Survey experiments are widely used across disciplines such as psychology, sociology, political sciences, and health sciences, as they allow for causality to be established between independent and dependent variables [44]. To manipulate water depth perception, the questionnaire included imagery portraying vehicle drivers before driving through flooded waterways. The imagery was chosen from free-to-use YouTube videos, in which drivers enter floodwaters and the water level on the vehicle is recorded. We established two scenarios with two sets of images. The main difference between the two scenarios was the depth of the water showed in the image (Supplementary Materials). The rest of the scene shows similar natural light, while the vehicles are in the background, without overshadowing the other features of the image. Participants were randomly assigned to one of two scenarios.

To eliminate possible bias related to the visual stimulation of water-depth perception represented by each scenario, the effect of the two images on water-depth perception was measured with a pre-test survey. In this pre-test, participants were randomly assigned to one out of four visual conditions, which tested the water depth perception with the same question over 4 different images (Supplementary Materials). In each case, four levels of water depth were suggested for selection from a graphical design (used also by Ahmed et al. [15]) that showed four versions of the same car submerged in four different water levels (Supplementary Materials). Only one answer was allowed. Respondents consisted of 200 Greek adults from the Pollfish audience (Pollfish utilizes a new survey methodology called random device engagement. By delivering your survey inside popular mobile apps, RDE utilizes an audience who are not taking premeditated surveys, by reaching them inside mobile apps they were using anyway. https:/ / resources.pollfish.com/pollfishschool/how-the-pollfish-methodology-works / (accessed on 15 April 2021). They included a percentage of $59 \%$ and $41 \%$ of males and females, respectively, with an average age of 35.8 years $(\mathrm{SD}=11.6)$, among which $44 \%$ have a university degree. A one-way ANOVA was conducted to compare the effect of the visualized floodwater on the water depth perception, and a Bonferroni multiple-comparison test was performed to select two images with a statistically significant difference in mean water depth perception (Table A1, Appendix A), which further constituted the two scenarios included in the final questionnaire. It should be noted that the difference in water depth perception between the selected pre-test images was consistent with the difference in depth recorded by the videos.

\subsection{Questionnaire}

Respondents were approached via an online questionnaire released by the https: / / www.meteo.gr/ (accessed on 15 April 2021) website, which provides weather, wave, lightning, and dust forecasts produced by the unit of meteorology (METEO) at the Institute for Environmental Research, National Observatory of Athens (IERSD/NOA) [45,46]. This website is the most popular meteorological website and among the 10 most visited websites of general interest in Greece. The average number of daily unique visitors on the website exceeds 350,000. Surveys related to weather hazards and individual behavioral attitudes are systematically posted with a very strong public response. This questionnaire was posted 
on 14 October 2020 and received 1940 valid responses within two days. An introductory text was intended to draw the participants' attention to the image shown.

The questionnaire contained 19 questions, 14 of which were considered in this study. Four questions covered the TPB beliefs (attitude, subjective norms, and PBC) of participants and their intention to enter floodwaters in 1 of the 2 scenarios, namely the "low water depth perception" scenario (LD-scenario, hereafter), and the "high water depth perception" scenario (HD-scenario, hereafter). The questionnaire also included questions addressing various contextual or situational control factors, such as the presence of signage, the distance from the final destination, and the case of an emergency $[18,20]$. Finally, the questionnaire included questions about past behavior associated with entering floodwaters, perception of risk associated with vehicle damage and health, and demographic characteristics (i.e., age, gender, family status, education level, and owned car size). The full questionnaire translated into English is available online in the Supplementary Materials.

In regard to the sample profile, participants in the main experiment were 1940 in total, 46\% (899) of which were assigned to the LD-scenario and 54\% (1041) of which were assigned to the HD-scenario. Overall, males were overrepresented, accounting for $75 \%$ of the population sample. We therefore controlled all statistical models for gender. Participants were normally distributed among the age categories between 18 and 70 years old, with $34 \%$ belonging to the $40-50$ years category. Only $0.8 \%$ of the participants were over 70 years old. In terms of education, $44 \%$ of participants reported a university degree. In regard to the family profile, the respective question aimed to capture whether the respondent was living alone $(23 \%)$, with other grown people $(22 \%)$, with children $(34 \%)$, or alone with children (21\%). In this order, the family profile was assumed to be associated with an increasing sense of responsibility against risky behavior. In terms of the car size, the vast majority of participants own either small (46\%) or large (50\%) passenger cars. Only $3 \%$ of participants were professional drivers, while $1 \%$ did not own a car at the time of the survey.

\subsection{Measures}

The model we built in the frame of this work includes one independent variable (water depth perception), one dependent variable (intention), three mediators (attitude, PBC, and subjective norm), a moderating variable (past behavior), and the control variables (control beliefs, risk perceptions, and demographics).

The independent variable (water depth perception) was dichotomous ( 1 = LD-scenario; 2 = HD-scenario). The dependent variable, namely the individual's intention to enter the floodwaters under the conditions captured by the image of each scenario (intention), was measured with one question at the beginning of the questionnaire. This question, as well as all measures except for demographic information and past behavior, was treated with a 5-point Likert rating scale [47]. On this scale, a score of 1 indicates the respondent's negative intention and a score of 5 the respondent's positive intention to enter floodwaters, if she/he was in the position of the pictured car driver.

All the psychometric scales used in the model as independent variables comprise multiple items measuring the same focal variable, i.e., attitude, PBC, and subjective norm. A minimum of three items per variable was chosen to ensure reliable and valid methodological treatment. Principal factor analysis (PFA) was applied to validate each multi-item variable and Cronbach's alpha $(\alpha)$ was applied to examine the scale internal reliability. Only items with factor loadings above 0.60 were accepted in PFA to ensure a very good fit with the factor [47]. To produce the model variables, the mean rating of all items comprising the variable was calculated [47]. Scale reliability was considered excellent for $\alpha$ above 0.7 [48]. Table 1 presents the statistical description of variables and items, the scale reliability of variables, and item factor loadings. 
Table 1. Statistics ( $n$, mean, standard deviation, scale construction, and reliability) for intention and predictor variables $(\min =1, \max =5)(\mathrm{n} 11=899, \mathrm{n} 21=1041)$. SD stands for standard deviation.

\begin{tabular}{|c|c|c|c|c|c|}
\hline \multirow[t]{2}{*}{ Model Variable ( $n$ ) } & \multicolumn{2}{|c|}{ LD Scenario } & \multicolumn{2}{|c|}{ HD Scenario } & \multirow{2}{*}{$\begin{array}{c}\text { Full Sample } \\
{\text { Cronbach's a }{ }^{2} / \text { Factor Item Loadings }{ }^{3}}^{3}\end{array}$} \\
\hline & Mean & SD & Mean & SD & \\
\hline Intention (1940) & 2.49 & 1.39 & 1.39 & 0.86 & \\
\hline Attitude (1940) & 2.28 & 1.03 & 1.53 & 0.80 & 0.87 \\
\hline Right & 2.01 & 1.10 & 1.33 & 0.81 & 0.91 \\
\hline Logical & 2.12 & 1.13 & 1.41 & 0.88 & 0.91 \\
\hline Risky & 3.29 & 1.24 & 4.14 & 1.12 & -0.67 \\
\hline PBC (1940) & 2.46 & 1.04 & 1.67 & 0.80 & 0.86 \\
\hline Self-capacity & 2.23 & 1.06 & 1.49 & 0.79 & 0.83 \\
\hline Self-efficacy & 2.68 & 1.16 & 1.85 & 0.95 & 0.82 \\
\hline Easy to decide & 2.65 & 1.30 & 3.33 & 1.48 & -0.2 \\
\hline Have control & 2.49 & 1.21 & 2.37 & 1.46 & 0.35 \\
\hline $\begin{array}{l}\text { Subjective norm (1940) } \\
\text { (in agreement with:) }\end{array}$ & 2.28 & 0.94 & 1.62 & 0.76 & 0.76 \\
\hline Appreciated people & 1.90 & 1.09 & 1.41 & 0.82 & 0.73 \\
\hline Co-driver & 1.84 & 1.11 & 1.31 & 0.72 & 0.75 \\
\hline Leading drivers & 3.09 & 1.32 & 2.14 & 1.21 & 0.63 \\
\hline Prevailing view & 1.67 & 1.04 & 1.32 & 0.83 & 0.55 \\
\hline \multirow[t]{2}{*}{ Past behavior ${ }^{1,4}(1225)$} & 0.73 & 0.43 & 0.68 & 0.47 & \\
\hline & $1=61 \%$ & & $1=51 \%$ & & \\
\hline \multicolumn{6}{|l|}{ Control beliefs (1940) } \\
\hline No warning sign at location & 2.02 & 1.22 & 1.36 & 0.83 & \\
\hline $\begin{array}{c}\text { Not aware of warnings for severe } \\
\text { weather at the location }\end{array}$ & 2.09 & 1.21 & 1.43 & 0.87 & \\
\hline Very close to the destination & 1.99 & 1.16 & 1.43 & 0.82 & \\
\hline Emergency & 2.98 & 1.30 & 2.21 & 1.19 & \\
\hline \multicolumn{6}{|l|}{ Risk perceptions (1940) } \\
\hline Health risk & 3.02 & 1.35 & 4.01 & 1.24 & \\
\hline Damage to car & 3.36 & 1.25 & 4.14 & 1.14 & \\
\hline
\end{tabular}

${ }^{1} \mathrm{n} 1, \mathrm{n} 2=$ population sample for LD-scenario and HD-scenario, respectively. Especially for past behavior, $\mathrm{n} 1=611$ and $\mathrm{n} 2=614$ (since responses with no experience were excluded). ${ }^{2}$ Cronbach's $\alpha>0.7$ show a highly reliable scale. ${ }^{3}$ Loadings $>0.60$ are accepted (Robinson, 2017). ${ }^{4}$ Coding of past behavior (of entering floodwater): $0=$ zero times, $1=1$ or more times.

To measure attitude, participants were asked to rate how (1) right, (2) logical, and (3) risky a decision to cross the stream shown in the picture would be. To measure perceived behavioral control ( $\mathrm{PBC}$ ), participants were asked three questions that addressed self-efficacy beliefs, i.e., if he/she would (1) have the capacity to perform the behavior, (2) effectively perform the behavior, (3) easily decide, and (4) have control of the situation in the driver's position. To examine subjective norm, participants were asked four questions about the extent to which the decision to cross the stream would be affected (1) by the approval of people they appreciate, (2) by the co-driver, (3) by drivers in front, and (4) by the personal belief that most people would do the same.

To measure past behavior, participants were asked two questions. The first one defined whether they ever came across floodwater (63\% of participants); thus, responses with negative answers were excluded from the past behavior measure. In the second question participants were asked how many times (none, one, or more) they crossed a flooded road or stream in bad (or questionable) weather conditions. The final construct of past behavior was dichotomous, i.e., past behavior was coded as 0 if the participant never tried to cross the stream, and as 1 if the participant did cross the stream.

Control factors, apart from demographics, were related to control beliefs and risk perception. To measure control beliefs, participants rated their intention to cross the stream shown in picture (1) if there was no warning sign, (2) if they were not informed of dangerous weather conditions for the wider area, (3) if they were close to the destination, and (4) if there was a need (Table 1). To measure risk perception variables, participants 
were asked to rate the risk associated with their life and car in case they decided to enter the floodwater in the image (Table 1).

\subsection{Statistical Analyses}

To test hypothesis H1, a one-way ANOVA was conducted to compare the effect of water depth perception on intention in low water depth (LD-scenario) and high water depth (HD-scenario) conditions.

A multiple mediation analysis was conducted to test hypothesis $\mathrm{H} 2$, namely that the TPB constructs mediate the effect of water depth perception on intention. We used a non-parametric bootstrapping procedure $(k=1000)$, involving bias-corrected confidence intervals and resampling techniques [23]. Bootstrapping does not require the sampling distribution of the indirect effect to be normal (an assumption that is usually violated in finite samples such as that of the present study) and has reasonable control over the Type I error rate [49]. We ran the mediation model with the independent variable of water depth perception, three mediators (attitude, subjective norm, and PBC), and intention as the dependent variable. The model was controlled for risk perceptions, control beliefs, and demographic attributes. Analyses were made using the SPSS statistical software.

Next, moderation mediation analysis [50] was conducted to test hypothesis $\mathrm{H} 3$, namely to investigate whether past behavior moderates the indirect effect of water depth perception on intention through the TPB factors. Again, 1000 bootstrap samples and a confidence interval of $95 \%$ were selected. In this model, we kept the structure of the initial mediation model and added past behavior as the moderator. Covariates were the same ones used in the mediation model.

\section{Results}

\subsection{Impact of Water Depth Perception on Intention}

A one-way ANOVA test indicated a significant effect of water depth perception on intention $(F(1,1938)=449.35, p<0.001)$. Specifically, the results showed that water depth perception has a negative and significant impact on intention, thus supporting hypothesis H1. The mean ratings of intention in the two water depth perception conditions are depicted in Figure 2. Specifically, the mean ratings of intention were as follows: 2.49 $(\mathrm{SE}=0.04$, confidence intervals $(\mathrm{CI})(2.41,2.56))$ for the LD-scenario, and $1.39(\mathrm{SE}=0.04, \mathrm{CI}$ $(1.32,1.46))$ for the HD-scenario.

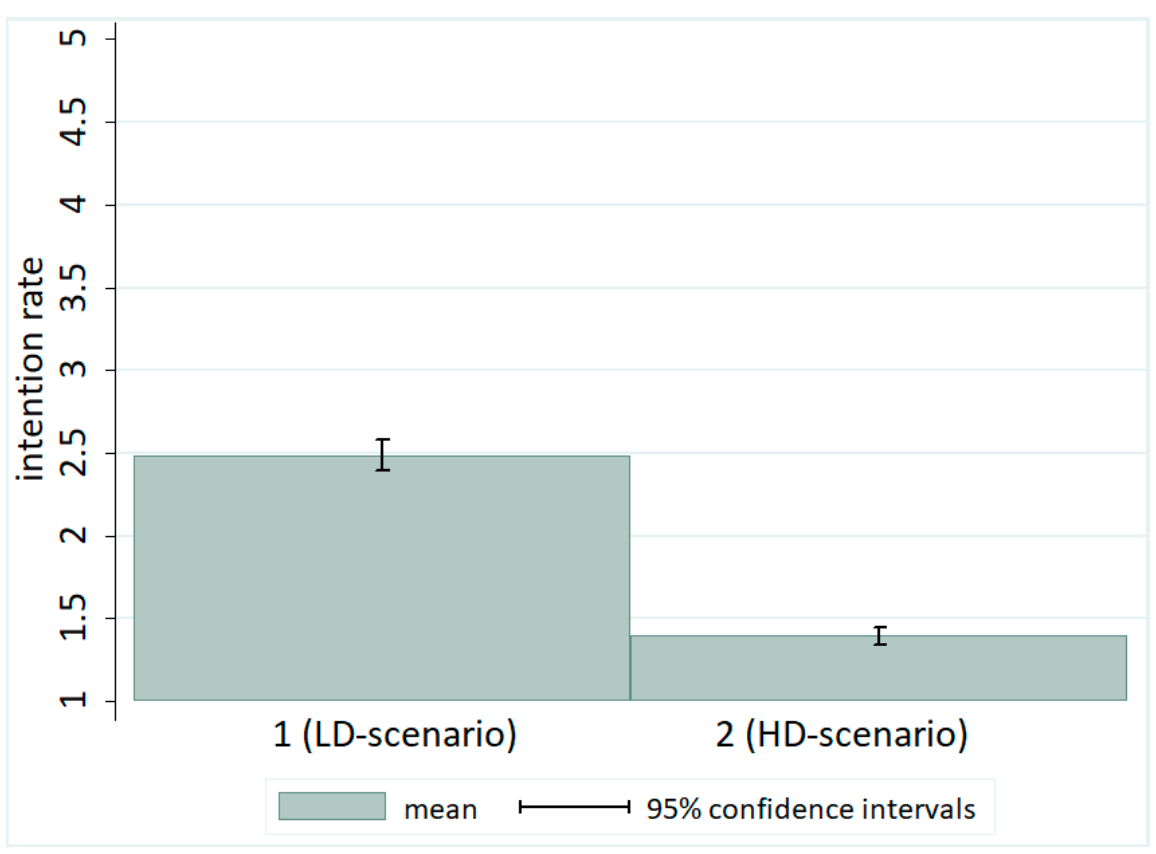

Figure 2. Mean ratings of intention for the different levels of water depth perception. 


\subsection{Mediation Analysis}

\subsubsection{Mediated Effect of Water Depth Perception}

Figure 3 displays the multiple mediation results. To test whether the TPB can provide a valid mechanism through which water depth perception affects intention, we checked whether the bias-corrected 95\% confidence intervals (CI) of the indirect effects of water depth perception on intention for each mediating variable contained the value of zero, which would imply no mediation. Indirect effects are provided in Figure 3. Namely, the calculated confidence intervals were as follows: $\mathrm{b}=-0.33, \mathrm{CI}(-0.41,-0.26)$ for attitude; $\mathrm{b}=-0.25, \mathrm{CI}(-0.31,-0.19)$ for PBC; $\mathrm{b}=-0.11, \mathrm{CI}(-0.15,-0.07)$ for subjective norm. The results were found to be significant, indicating that attitude, $\mathrm{PBC}$, and subjective norm mediate the relationship between water depth perception and intention, thus supporting the validity of hypothesis 2 . The negative coefficients indicated that a change of water depth perception from low to high causes a decrease in intention due to the underlying mechanism related to the TPB factors.

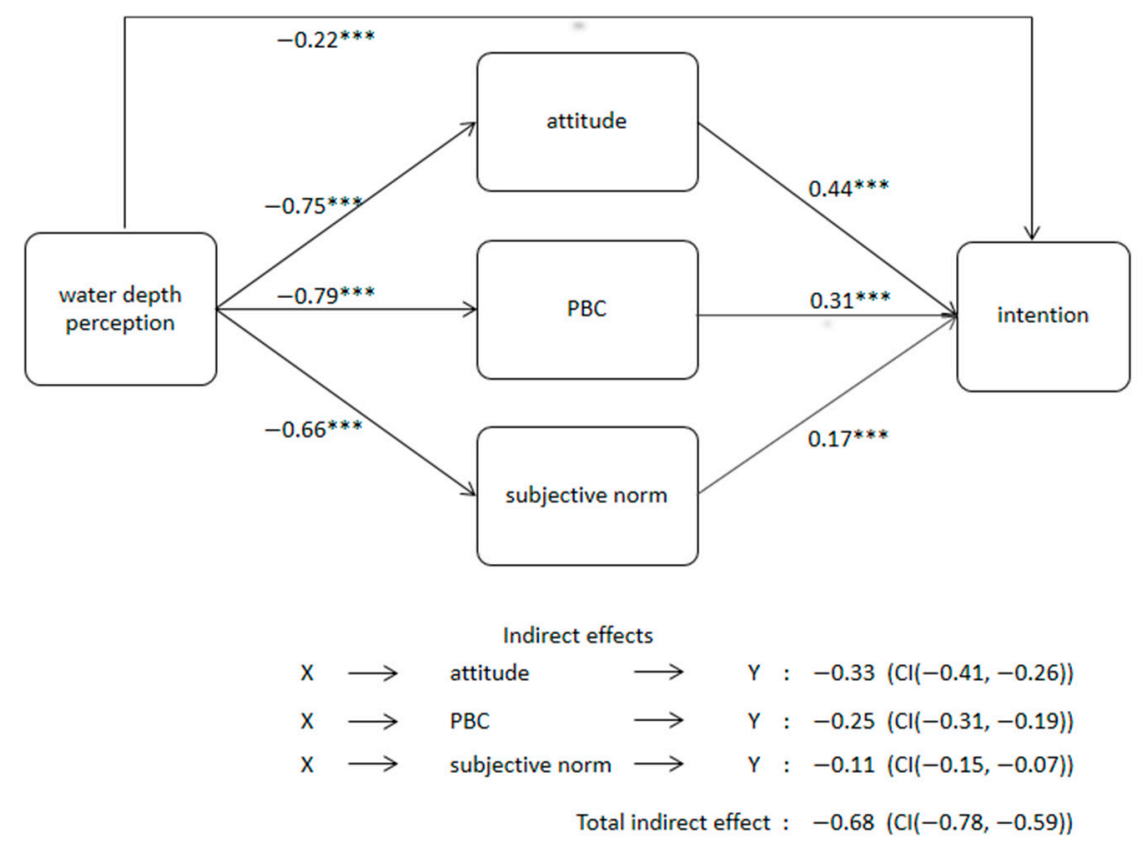

Figure 3. Model results showing the TPB mediating the effect of water depth perception on drivers' intention to enter floodwaters. All direct effects were significant $\left.{ }^{* * *} p<0.001\right)$. Indirect effect coefficients and the $95 \%$ bootstrap confidence interval indicate that the TPB variables significantly mediate the relationship between water depth perception $(\mathrm{X})$ and intention $(\mathrm{Y})$.

The total mediated effect of water depth perception on intention $(b=-0.68, \mathrm{CI}(-0.78$, $-0.59)$ ) was considerably higher than its direct effect $(b=-0.22$, $\mathrm{SE}=0.03, p<0.001)$, by a factor of 3 (Figure 3). This indicates that water depth perception was highly mediated by the TPB variables, while only a small part of the effect was not explained by the examined variables. Among the mediating variables, attitude was found to be the strongest, as it was responsible for almost half of the total indirect effect. The effect of subjective norm was found to be lower by a factor of 3 compared to attitude, and approximately by a factor of 2 compared to PBC; thus, it was the weakest mediator.

\subsubsection{Direct Effects of TPB Constructs and Water Depth Perception on Intention}

The direct effects of attitude, $\mathrm{PBC}$, and subjective norm on intention were positive and significant $(\mathrm{b}=0.44, \mathrm{SE}=0.03, p<0.001, \mathrm{CI}(0.39,0.49)$ for attitude; $\mathrm{b}=0.31, \mathrm{SE}=0.03$, $p<0.001, \mathrm{CI}(0.26,0.37)$ for PBC; and $\mathrm{b}=0.17, \mathrm{SE}=0.03, p<0.001, \mathrm{CI}(0.12,0.22)$ for subjective norm). Among the TPB variables, attitude had the strongest direct effect on 
intention, i.e., 2.6 times higher than the subjective norm effect and 1.4 times higher than the PBC effect.

The direct effect of water depth perception on intention was negative and significant $(b=-0.22, \mathrm{SE}=0.03, p<0.001, \mathrm{CI}(-0.28,-0.15))$. The multiple mediation model also estimated the direct effects of the independent water depth perception on the mediators. These were all negative and significant $(b=-0.75, \mathrm{SE}=0.04, p<0.001, \mathrm{CI}(-0.83,-0.66)$ for attitude; $\mathrm{b}=-0.79, \mathrm{SE}=0.04, p<0.001, \mathrm{CI}(-0.87,-0.70)$ for PBC; and $\mathrm{b}=-0.66, \mathrm{SE}=0.04$, $p<0.001, \mathrm{CI}(-0.73,-0.58)$ for subjective norm). PBC was found to be more affected by water depth perception, even though differences between the direct effects of water depth perception on the TPB variables were small.

\subsubsection{Effects of Control Factors}

Among the various control factors, risk perception associated with potential car damage $(b=-0.09, \mathrm{SE}=0.03, p<0.001, \mathrm{CI}(-0.14,-0.04))$, the control belief associated with the absence of a warning sign at the location $(b=0.07, \mathrm{SE}=0.02, p=0.008, \mathrm{CI}(0.02$, $0.11)$ ), and gender $(\mathrm{b}=-0.07, \mathrm{SE}=0.04, p=0.045, \mathrm{CI}(-0.15,-0.00))$ were found to have a significant effect on intention. Males were found to be associated with a lower intention than women; however, the effect was weak and had a low significance. No significant effects were found for the rest of the demographic variables (age, education, family status, and car size), health risk perception, and the rest of the control beliefs.

\subsection{Moderating Effect of Past Behavior}

The moderated mediation model results showed that past behavior is a significant moderator of the indirect effect of water depth perception on intention through attitude. The conditional indirect effect of water depth perception on intention through attitude was found to be significant at both low and high values of past behavior, namely at past behavior $=0(b=-0.25, S E=0.06, C I(-0.39,-0.15))$ and past behavior $=1(b=-0.39$, $\mathrm{SE}=0.06, \mathrm{CI}\left(-0.51,-0.29 \_\right)$. Importantly, the test of equality of the conditional indirect effects was also significant $(b=-0.14, \mathrm{SE}=0.06, \mathrm{CI}(-0.25,-0.03)$. Therefore, past behavior was found to further increase the negative indirect effect that water depth perception has on intention through attitude. Conversely, the conditional indirect effects of water depth perception on intention through PBC and subjective norm were not found significant as the bias-corrected 95\% confidence intervals (CI) contained the value of zero. Thus, hypothesis 3 was only partly supported.

\section{Discussion}

Overall, the findings confirmed the working hypothesis that the effect of risk-induced environmental factors on drivers' intention to enter floodwaters can be significant and is driven by a mechanism of psychological processes, and conditionally influenced by past behavior. In this context, the TPB proves to be a valuable tool for understanding further the relationship between situational parameters and individual behavior.

The experiment conducted in this study manipulated water depth perception ensuring safe conclusions as to the causal relationships established. In the pre-test of the experiment, we calibrated perceived water depth; this enabled us to provide accurate and reliable evidence showing that, in the case of perceived higher water depth, drivers' intention to pursue risky behavior weakens. The present research thus provides evidence indicating that the environmental context should not be ignored, as this would lead to an underestimation of the importance of situational factors in risk-taking behaviors.

All three TPB constructs were found to have a positive impact on intention. This indicates a very consistent theoretical framework, showing the strong influence of psychological factors in decision-making. Especially when it comes to entering floodwater, the results confirm the findings of previous works $[15,16,20]$. Amongst the TPB factors, attitude had consistently the strongest effect on intention, while subjective norm was found to be the weakest predictor, similar to previous works $[20,27,51]$. 
The mediation analysis revealed that the TPB constructs explain the largest part of the total effect of water depth perception on intention. Therefore, we can strongly argue that the underlying psychological mechanisms are associated to a high degree with personal beliefs and attitudes. In this study, mediation was mainly credited to attitude. Specifically, half of the indirect effect was attributed to attitude, which thus can be considered more susceptible to the water depth perception compared to perceived behavioral control and subjective norm. The latter was found to be the weakest chain of the mediation mechanism. The findings indicate that, when called upon to assess the critical situation (as informed by environmental/situational cues) and act accordingly, individuals take less account of the validation of the impending behavior by those around them, take more account of their abilities, and much more of how they evaluate their behavior of entering into the flooded area (e.g., harmful).

In addition, the present study demonstrates that the past behavior interacts with water depth perception to further affect intention, primarily through attitude. The results indicated that drivers' behavior-favorable attitude and intention were more susceptible to the perceived water depth when they had previously crossed flooded streams or pathways. Again, attitude plays a key role in the transfer of information related to the earlier behavior in subsequent intention. It is worth noting that the negative effect of past behavior on the intention, given the water depth perception, may be an indication that drivers that eventually crossed the inundated area were left with a negative impression, while drivers that did not cross it may not anticipate a negative experience. The practical implication of this finding is very strong, as it reinforces the need for impact-based warnings that inform about the risks and the expected negative experiences [52].

Regarding practical implications, the findings of this work are useful to guide interventions and shape policies that aim to change the behavior of drivers facing similar situations of risk. Especially in light of the increasing trend of vehicle-related flood fatalities [53], and the huge costs involved in developing large-scale infrastructure to keep drivers away from rivers, any initiatives in the direction of behavioral interventions would be very beneficial for the protection of drivers.

In this area, the traits found in TPB factors, past behavior, and perception should be exploited to shape the interventions aiming to influence driver behavior. In detail, such policies should encompass different intervention tactics including training, warning signs, and other informational material that focuses on devaluing dangerous behavior, on the danger of overestimating individual capabilities, and on the disapproval of driving through flooded roads or streams [34,54].

Concerning the effect of perceived water depth, the results of this study suggest that presenting drivers with distinctive cues that highlight environmental elements that denote high hazards (such as the high or unknown water depth) has the potential to discourage them from entering floodwaters (i.e., negative effect on intention). Such cues could have the form of water depth indicators coupled with active warning signs [55] aiming to communicate the risks of driving through high water by highlighting the element of water depth to vehicle occupants. To this end, active road signage is considered to be more effective in highlighting or drawing the attention of the drivers to environmental cues denoting a high risk than passive signs. Additionally, messages and personalized warnings through navigation software could act as reminders of the potential situational context of risky environments. In general, techniques that emphasize the potentially high water depth and messages that will lead the drivers to visualize or appreciate the conditions of a flooded passage as adverse or high-risk should be incorporated in future campaigns. In the same context, the imagery of the right environmental cues that often lead to dangerous situations for drivers can be used for training material or simulations. This type of learning/training and its strength has been acknowledged in previous works [56]. This way, in real situations, drivers can identify the same cues or environmental stimuli that they have already seen in training, triggering a desired reaction or behavior [15]. Simulating real conditions in training would be ideal, as, despite the strength of past experiences in influencing risk 
perception positively, it is obvious that we cannot recommend "learning through real experience" in this case due to safety reasons.

The implications of the present findings are extending to road safety policy, a major societal issue that is high on the European agenda for mobility and transport [57]. In this context, the critical role of road user behavior is recognized; therefore, education and training are considered essential to ensure the effectiveness of a road safety policy. As the key to achieving this goal is the whole licensing process, the findings on the parameters that affect the driver's intention to engage in dangerous behavior can effectively help to improve the curriculum.

On the methodological front, this study demonstrates that the use of imagery in surveys has the potential to elicit factors, such as environmental cues, that may not be easily identifiable in traditional surveys. Research using imagery-enriched questionnaires should be further explored.

Regarding the limitations of the present study, it has to be noted that the participants' perception of water depth is most probably subjective, as both the authors and the survey participants have no means of knowing exactly how deep floodwater was in the images included with the questionnaire. Nevertheless, it is drivers' subjective judgment that influences decision-making and subsequently determines their behavior in the face of floodwaters. Thus, the subjective or perceptive understanding of water depth is very much the factor of interest in this study.

Another limitation concerns a portion of the answers that describe the participants' hypothetical actions. These answers may be susceptible to the social desirability bias, as participants may perceive some of the answers (e.g., crossing a flooded stream) as socially unacceptable or objectionable behaviors [58]. Finally, the most important limitation associates with the possible role of urgency in one's decision-making process. The participants of this study were not in an emergency. Given that in these types of situations drivers may override their intention as indicated by the TPB, there could be a percentage of people that may not act based on the projections of this study and other studies that use the TPB model. Besides, the TPB model is likely to not account for the impulsive nature of decision-making that may take place for some of the drivers under real conditions. However, this percentage is expected to be very limited given the very consistent results on the TPB's ability to predict behavioral intention. Besides, previous research on flood mortality has shown that only a very small number of fatalities are caused by individuals who are motivated by something that would be considered an emergency (e.g., rescuing someone or something and others) [12].

\section{Conclusions}

This research shows that water depth perception acts as a significant environmental cue that informs car drivers about the weather-related hazard and affects their intention to enter floodwater. Furthermore, this study shows that behavioral psychology and past behavior can explain why, how, and under which conditions people respond to risk-inducing situational factors. As weather-related disasters are of increasing concern, studies like this, which reveal subtle and complex interactions of human behavior with the surrounding, contribute to a deeper understanding of the role of the human factor in the magnitude of adverse effects. The current trend in dealing with weather-related disasters is to adopt measures to reach out and inform citizens with new and more effective practices that take into account the individual's response to emergencies. Therefore, the findings of this study can be used as part of an overall strategy to reduce the impact of weather-related disasters. 
Supplementary Materials: The following are available online at https:/ /www.mdpi.com/article/10 $.3390 /$ su13084451/s1, Survey Experiment.

Author Contributions: Conceptualization, K.P. and M.D.; methodology, K.P., G.P., and M.D.; software, K.P.; validation, K.P., G.P., V.K., K.L., and M.D.; formal analysis, K.P., G.P., V.K., K.L., and M.D.; investigation, M.D. and K.P.; resources, M.D.; data curation, K.P. and G.P.; writing-original draft preparation, K.P. and M.D.; writing-review and editing, V.K.; visualization, K.P. All authors have read and agreed to the published version of the manuscript.

Funding: This research received no external funding.

Institutional Review Board Statement: Not applicable.

Informed Consent Statement: Not applicable.

Data Availability Statement: The online questionnaire is available in the Supplementary Materials to this article. The complete data set can be shared only in the context of scientific cooperation as it is intended to be used in post-survey analyses.

Conflicts of Interest: The authors declare no conflict of interest.

\section{Appendix A}

Pre-test results.

An analysis of variance (Table A1) showed that the effect of the visualized floodwater on the water depth perception was significant, $\mathrm{F}(3,196=6.11, p<0.001$. A Bonferroni post-hoc test revealed that perception was statistically significant $(p<0.005)$ and higher for images 1,2 , and 4 compared to image 3 . There were no statistically significant differences $(p>0.05)$ between images 1,2, and 4 (Table A1). Images 3 and 4 were finally selected for the main experiment.

Table A1. Analysis of variance (one-way ANOVA) and comparison of water depth perception by image (Bonferroni).

\begin{tabular}{|c|c|c|c|c|c|}
\hline \multicolumn{6}{|c|}{ ANOVA } \\
\hline \multicolumn{6}{|c|}{ Water depth perception } \\
\hline & Sum of squares & $\mathrm{df}$ & Mean square & $\mathrm{F}$ & Sig. \\
\hline Between groups & 11.51 & 3 & 3.84 & 6.11 & 0.000 \\
\hline Within groups & 123.11 & 196 & 0.63 & & \\
\hline Total & 134.62 & 199 & 0.68 & & \\
\hline \multicolumn{6}{|c|}{ Bonferroni multiple comparison test ${ }^{1}$} \\
\hline & Image 1 & Image 2 & Image 3 & & \\
\hline Image 2 & 0.01 & & & & \\
\hline Image 3 & $-0.59 * * *$ & $-0.60 * * *$ & & & \\
\hline Image 4 & 0.00 & -0.01 & & & \\
\hline
\end{tabular}

Notes: The pre-test questionnaire and images are provided as Supplementary Materials. ${ }^{1}$ Statistical significance: $(* * *) p<0.005$.

\section{References}

1. Kotlyakov, V.M.; Desinov, L.V.; Dolgov, S.V.; Koronkevich, N.I.; Likhacheva, E.A.; Makkaveev, A.N.; Medvedev, A.; Rudakov, V.A. Flooding of July 6-7, 2012, in the town of Krymsk. Reg. Res. Russ. 2013, 3, 32-39. [CrossRef]

2. Petrucci, O.; Aceto, L.; Bianchi, C.; Bigot, V.; Br, R.; Pereira, S.; Kahraman, A.; Kılıç, Ö.; Kotroni, V.; Llasat, M.C.; et al. Flood Fatalities in Europe, 1980-2018: Variability, Features, and Lessons to Learn. Water 2019, 11, 1682. [CrossRef]

3. Jonkman, S.N.; Kelman, I. An analysis of the causes and circumstances of flood disaster deaths. Disasters 2005, $29,75-97$. [CrossRef] [PubMed]

4. Ruin, I.; Creutin, J.-D.; Anquetin, S.; Gruntfest, E.; Lutoff, C. Human vulnerability to flash floods: Addressing physical exposure and behavioural questions. In Flood Risk Management: Research and Practice; Taylor \& Francis Group: London, UK, 2009; pp. 1005-1012.

5. Wilson, T. Les risques de blessures et de décès par imprudence lors des inondations. Responsab Environ. 2007, $43,57-63$.

6. Staes, C.; Orengo, J.C.; Malilay, J.; Rullan, J.; Noji, E. Deaths due to Flash Floods in Puerto Rico, January 1992: Implications for Prevention. Int. J. Epidemiol. 1994, 23, 968-975. [CrossRef]

7. Coates, L. Flood fatalities in Australia, 1788-1996. Aust. Geogr. 1999, 30, 391-408. [CrossRef] 
8. Becker, J.S.; Taylor, H.L.; Doody, B.J.; Wright, K.C.; Gruntfest, E.; Webber, D. A review of people's behavior in and around floodwater. Weather Clim. Soc. 2015, 7, 321-332. [CrossRef]

9. Ashley, S.T.; Ashley, W.S. Flood fatalities in the United States. J. Appl. Meteorol. Climatol. 2008, 47, 805-818. [CrossRef]

10. Terti, G.; Ruin, I.; Anquetin, S.; Gourley, J.J. A situation-based analysis of flash flood fatalities in the United States. Bull. Am. Meteorol. Soc. 2017, 98, 333-345. [CrossRef]

11. Fitzgerald, G.; Du, W.; Jamal, A.; Clark, M.; Hou, X. Flood Fatalities in Contemporary Australia. Emerg. Med. Australas. 2010, 20, 180-186. [CrossRef]

12. Diakakis, M. Types of behavior of flood victims around floodwaters. Correlation with situational and demographic factors. Sustainability 2020, 12, 4409. [CrossRef]

13. Weyrich, P.; Scolobig, A.; Walther, F.; Patt, A. Responses to severe weather warnings and affective decision-making. Nat. Hazards Earth Syst. Sci. 2020, 20, 2811-2821. [CrossRef]

14. Papagiannaki, K.; Kotroni, V.; Lagouvardos, K.; Ruin, I.; Bezes, A. Urban area response to flash flood-triggering rainfall, featuring human behavioral factors: The case of 22 October 2015 in Attica, Greece. Weather Clim. Soc. 2017, 9, 621-638. [CrossRef]

15. Ahmed, M.A.; Haynes, K.; Tofa, M.; Hope, G.; Taylor, M. Duty or safety? Exploring emergency service personnel's perceptions of risk and decision- making when driving through floodwater. Prog. Disaster Sci. 2020, 5, 100068. [CrossRef]

16. Pearson, M.; Hamilton, K. Investigating driver willingness to drive through flooded waterways. Accid. Anal. Prev. 2014, 72, 382-390. [CrossRef]

17. Ajzen, I. The Theory of Planned Behavior. Organ Behav. Hum. Decis. Process. 1991, 50, 179-211. [CrossRef]

18. Hamilton, K.; Peden, A.E.; Pearson, M.; Hagger, M.S. Stop there' s water on the road! Identifying key beliefs guiding people' s willingness to drive through flooded waterways. Saf. Sci. 2016, 89, 308-314. [CrossRef]

19. Hamilton, K.; Demant, D.; Peden, A.; Hagger, M. A systematic review of human behaviour in and around floodwater. Int. J. Disaster Risk Reduct. 2020, 47, 101561. [CrossRef]

20. Hamilton, K.; Peden, A.E.; Keech, J.J.; Hagger, M.S. Changing people's attitudes and beliefs toward driving through floodwaters: Evaluation of a video infographic. Transp. Res. Part F Traffic Psychol. Behav. 2018, 53, 50-60. [CrossRef]

21. Zhong, S.; Clark, M.; Hou, X.Y.; Zang, Y.L.; FitzGerald, G. Queensland floods: Using H addon's M atrix to define and categorise public safety strategies. Emerg. Med. Australas. 2013, 25, 345-352. [CrossRef]

22. Ajzen, I. The theory of planned behaviour is alive and well, and not ready to retire: A commentary on Sniehotta, Presseau, and Araújo-Soares. Health Psychol. Rev. 2014, 9, 131-137. [CrossRef]

23. Preacher, K.J.; Hayes, A.F. Asymptotic and resampling strategies for assessing and comparing indirect effects in multiple mediator models. Behav. Res. Methods 2008, 40, 879-891. [CrossRef] [PubMed]

24. Drobot, S.D.; Benight, C.; Gruntfest, E.C. Risk factors for driving into flooded roads. Environ. Hazards 2007, 7, 227-234. [CrossRef]

25. Ajzen, I. From intentions to actions: A theory of planned behavior. In Action Control; Kuhl, J., Beckmann, J., Eds.; Springer: Berlin/ Heidelberg, Germay, 1985; pp. 11-39. [CrossRef]

26. Bandura, A. Self-Efficacy: The Exercise of Control; Freeman and Company: New York, NY, USA, 1997.

27. Armitage, C.J.; Conner, M. Efficacy of the Theory of Planned Behaviour: A Meta-Analytic Review. Br. J. Soc. Psychol. 2001, 40, 471-499. [CrossRef] [PubMed]

28. Ajzen, I.; Fishbein, M. The influence of attitudes and behavior. In The Handbook of Attitudes; Albarracin, D., Johnson, B.T., Zanna, M.P., Eds.; Lawrence Erlbaum Associates Publishers: Mahwah, NJ, USA, 2005; pp. 173-221.

29. de Leeuw, A.; Valois, P.; Ajzen, I.; Schmidt, P. Using the theory of planned behavior to identify key beliefs underlying proenvironmental behavior in high-school students: Implications for educational interventions. J. Environ. Psychol. 2015, 42, 128-138. [CrossRef]

30. Sommer, L. The Theory Of Planned Behaviour And The Impact Of Past Behaviour. Int. Bus. Econ. Res. J. 2011, 10, 91-110. [CrossRef]

31. Conner, M.; Armitage, C.J. Extending the theory of planned behavior: A review and avenues for further research. J. Appl. Soc. Psychol. 1998, 28, 1429-1464. [CrossRef]

32. Elliott, M.A.; Armitage, C.J.; Baughan, C.J. Drivers' Compliance with Speed Limits: An Application of the Theory of Planned Behavior. J. Appl. Psychol. 2003, 88, 964-972. [CrossRef]

33. Bamberg, S.; Masson, T.; Brewitt, K.; Nemetschek, N. Threat, coping and flood prevention-A meta-analysis. J. Environ. Psychol. 2017, 54, 116-126. [CrossRef]

34. Hamilton, K.; Price, S.; Keech, J.J.; Peden, A.E.; Hagger, M.S. Drivers' experiences during floods: Investigating the psychological influences underpinning decisions to avoid driving through floodwater. Int. J. Disaster Risk Reduct. 2018, 28, 507-518. [CrossRef]

35. Steinmetz, H.; Knappstein, M.; Ajzen, I.; Schmidt, P.; Kabst, R. How effective are behavior change interventions based on the theory of planned behavior?: A three-level meta analysis. Z. Psychol. 2016, 224, 216-233. [CrossRef]

36. Papagiannaki, K.; Kotroni, V.; Lagouvardos, K.; Papagiannakis, G. How awareness and confidence affect flood-risk precautionary behavior of Greek citizens: The role of perceptual and emotional mechanisms. Nat. Hazards Earth Syst. Sci. 2019, 19, $1329-1346$. [CrossRef]

37. Terpstra, T. Emotions, Trust, and Perceived Risk: Affective and Cognitive Routes to Flood Preparedness Behavior. Risk Anal. 2011, 31, 1658-1675. [CrossRef] 
38. Taylor, F.; Archer, F.; Bird, D.; Paton, D. Lessons From the Floodsafe Program: Why People Do and Do Not Prepare for Floods. In Proceedings of the 56th Floodplain Management Australia Conference, Nowra, Australia, 17-20 May 2016; pp. 1-11.

39. Ajibade, I.; McBean, G.; Bezner-Kerr, R. Urban flooding in Lagos, Nigeria: Patterns of vulnerability and resilience among women. Glob. Environ. Chang. 2013, 23, 1714-1725. [CrossRef]

40. Gissing, A.; Haynes, K.; Coates, L.; Keys, C. Motorist behaviour during the 2015 Shoalhaven floods. Aust. J. Emerg. Manag. 2016, 31, 25-31.

41. Byrnes, J.P.; Miller, D.C.; Schafer, W.D. Gender differences in risk taking: A metaanalysis. Psychol. Bull. 1999, 125, 367-383. [CrossRef]

42. Perdue, B.C.; Summers, J.O. Checking the Success of Manipulations in Marketing Experiments. J. Mark. Res. 1986, 23, 317. [CrossRef]

43. Hunt, S.D.; Sparkman, R.D.; Wilcox, J.B. The Pretest in Survey Research: Issues and Preliminary Findings. J. Mark. Res. 1982, 19, 269-273. [CrossRef]

44. Kalkhoff, W.; Youngreen, R.; Nath, L.; Lovaglia, M.J. Human Participants in Laboratory Experiments in the Social Sciences, 2nd ed.; Elsevier Inc.: Amsterdam, The Netherlands, 2014; pp. 103-126. [CrossRef]

45. Lagouvardos, K.; Kotroni, V.; Koussis, A.; Feidas, H.; Buzzi, A.; Malguzzi, P. The meteorological model BOLAM at the National Observatory of Athens: Assessment of two-year operational use. J. Appl. Meteorol. 2003, 42, 1667-1678. [CrossRef]

46. Lagouvardos, K.; Kotroni, V.; Bezes, A.; Koletsis, I.; Kopania, T.; Lykoudis, S.; Mazarakis, N.; Papagiannaki, K.; Vougioukas, S. The automatic weather stations NOANN network of the National Observatory of Athens: Operation and database. Geosci. Data J. 2017, 4, 4-16. [CrossRef]

47. Robinson, M.A. Using multi-item psychometric scales for research and practice in human resource management. Hum. Resour. Manag. 2018, 57, 739-750. [CrossRef]

48. Nunnally, J.C. Psychometric Theory, 3rd ed.; TataMcGraw-Hill Education: New York, NY, USA, 1994.

49. Hayes, A.F. Beyond Baron and Kenny: Statistical mediation analysis in the new millennium. Commun. Monogr. 2009, 76, 408-420. [CrossRef]

50. Hayes, A.F. Introduction to Mediation, Moderation, and Conditional Process Analysis: A Regression-Based Approach; Guilford Publications: New York, NY, USA, 2013; p. 193.

51. Hagger, M.S.; Chatzisarantis, N.L.D.; Biddle, S.J.H. The influence of autonomous and controlling motives on physical activity intentions within the Theory of Planned Behaviour. Br. J. Health Psychol. 2002, 7, 283-297. [CrossRef]

52. Kaltenberger, R.; Schaffhauser, A.; Staudinger, M. "What the weather will do"-Results of a survey on impact-oriented and impact-based warnings in European NMHSs. Adv. Sci. Res. 2020, 17, 29-38. [CrossRef]

53. Diakakis, M. Have flood mortality qualitative characteristics changed during the last decades? The case study of Greece. Environ. Hazards 2016, 15, 148-159. [CrossRef]

54. Scott-Parker, B.; Watson, B.; King, M.J.; Hyde, M.K. “ They're lunatics on the road”: Exploring the normative influences of parents, friends, and police on young novices' risky driving decisions. Saf. Sci. 2012, 50, 1917-1928. [CrossRef]

55. Sharif, H.O.; Hossain, M.; Jackson, T.; Bin, S. Person-place-time analysis of vehicle fatalities caused by flash floods in Texas. Geomat. Nat. Hazards Risk 2012, 3, 311-323. [CrossRef]

56. Hagger, M.S.; Lonsdale, A.; Koka, A.; Hein, V.; Pasi, H.; Lintunen, T.; Chatzisarantis, N.L.D. An intervention to reduce alcohol consumption in undergraduate students using implementation intentions and mental simulations: A cross-national study. Int. J. Behav. Med. 2012, 19, 82-96. [CrossRef] [PubMed]

57. European Commission. Towards a European Road Safety Area: Policy Orientations on Road Safety 2011-2020; p. 16. Available online: https:/ / ec.europa.eu/transparency/regdoc/rep/1/2010/EN/1-2010-389-EN-F1-1.Pdf (accessed on 15 April 2021).

58. Beck, L.; Ajzen, I. Predicting Dishonest Actions Using the Theory of Planned Behavior. J. Res. Personal. 1991, 301, $285-301$. [CrossRef] 